This article is $\odot$ Emerald Group Publishing and permission has been granted for this version to appear here (https://dspace.lib.cranfield.ac.uk/index.jsp). Emerald does not grant permission for this article to be further copied/distributed or hosted elsewhere without the express permission from Emerald Group Publishing Limited.

www.emeraldinsight.com

Paper Title: $\quad$ Scoping the Contextual Issues That Influence Shrinkage Measurement

Publication details: International Journal of Retail \& Distribution Management.

Vol. 34 No. 11, 2006

pp. 860-872

Authors:

Paul Chapman ${ }^{1}$

Senior Research Fellow

Cranfield School of Management,

Cranfield University.

Bedfordshire. MK43 0AL

United Kingdom.

Telephone +441234 751122

Fax +441234 751712

Email: $\quad$ Paul.chapman@cranfield.ac.uk

Simon Templar

Teaching Fellow

Cranfield School of Management,

Cranfield University.

${ }^{1}$ Corresponding author 


\section{Scoping THE ConTEXTUAL IsSUES ThAT INFLUENCE SHRINKAGE}

\section{MEASUREMENT}

\section{Structured abstract}

\section{Purpose}

Measures and measurement systems must reflect the context to which they are applied (Neely, 1999), requiring that the contextual issues relating to retail shrinkage must be identified as a necessary precursor when measuring shrinkage. Without considering these issues any decision on which method of shrinkage measurement to employ will be uninformed, arbitrary and at best intuitive.

\section{Methodology / Approach}

The methodology adopted was a scoping study of the key issues that influence shrinkage measurement, drawing these from prior research and exposing these findings to the informed opinion of a review panel for critique and to highlight areas for further investigation.

\section{Findings}

The findings from the study were to identify a range of contextual issues relating to shrinkage and to summarise these issues into four categories, namely:

- Stewardship and performance improvement.

- Cost reduction and sales improvement.

- Local effects of systemic issues.

- The detailed nature of retailing.

\section{Implications}

The implications of these key issues are significant to the measurement of shrinkage in terms of the scope across the business from which shrinkage needs to be considered. This finding highlights the need to consider shrinkage as a systemic issue that extends across a business from design, through planning to operational execution. It also identifies the impact of shrinkage on increasing cost and depressing sales and considers the responsibility of management teams in addressing these matters.

\section{Originality / value of paper}

This paper is theoretically original and thus of value to the academic community. It is also of value to the practitioner community in grocery retailing where shrinkage and its measurement is of worldwide strategic importance.

Paper Category: $\quad$ Conceptual Paper

Keywords: $\quad$ Shrinkage Measurement 


\section{Introduction}

Grocery retailing is a significant industrial activity, for example in Europe the turnover of the sector exceeded $€ 1000$ billion in 2003 (Beck, 2004). This business sector can be characterised as a complex, highly competitive market made up of a diverse population of organisations. Across this varied business landscape cuts the common issue of shrinkage. Recent research into shrinkage has shown it to be an important issue for organisations to consider, not least because shrinkage is a significant cost to the FMCG grocery industry. Taking Europe as an example, shrinkage cost the sector €24 billion in 2003 (Beck, 2004).

Performance measurement has an important role to play in the efficient and effective management of organisations (Neely, 1999) and this is certainly the case when it comes to the management of shrinkage. Given that measures and measurement systems must reflect the context to which they are applied (Neely, 1999), the objective of this paper is to scope out and summarise the contextual issues surrounding retail shrinkage in Europe's grocery sector and to offer a view on the implications of these issues to shrinkage measurement.

\section{Shrinkage}

Shrinkage is a significant issue to retailers as it has a major impact upon profitability in this relatively low margin sector (Beck, 2004; Bernstein, 1963). Shrinkage is also a resilient problem despite concerted efforts to address it spanning more then forty years (see for example Bernstein, 1963; Donnell, 1975). Efforts to address shrinkage are hampered by the ease with which it can be viewed incorrectly. Indeed, the degree to which shrinkage is misunderstood has led current understanding of shrinkage to be described as, "myopic" (Beck, Chapman and Peacock, 2003). It has been long known that shrinkage is frequently attributed to the wrong cause (Bernstein, 1963). For example, retailers often emphasise external theft as a cause of shrinkage as they are in denial of the level of theft by their own employees and therefore retailers underreport internal theft (Oliphant and Oliphant, 2001).

A key culprit in the misunderstanding of shrinkage is the widespread misreporting of findings from industry surveys. Surveys are a valuable research instrument however they have their limitations and caution needs to be applied when conducting surveys and when reporting their findings. When conducting surveys, accurate data can only be achieved if there are accurate processes generating the data (Biemer and Lyberg, 2003). Beck (2004) reports that most shrinkage (51\%) is unknown. Therefore the values attributed by survey respondents to various causal categories for total (known and unknown) shrinkage lack rigor. The findings reported from such surveys need to be considered against the question raised by Easterby-Smith, Thorpe and Lowe (1991) when considering research design, "Is it the things themselves, or the people's views about them, that are important?" With most shrinkage being unknown, research into this topic lacks a foundation of measured, quantified material which means that surveys have little value as a means of describing the nature of shrinkage, the 'thing' in this instance. Instead the value of industry surveys lies in measuring the respondent's views on the causes of shrinkage. Taken from this perspective, these surveys are a valuable source of data to study the attribution process as a topic in itself and explore shortcomings such as self-motivational biases, where failures are attributed to external factors in order to maintain self-esteem (Ross and Anderson, 1982) which may help explain why external theft is often emphasised, as described above. 
However this is not the perspective generally taken when analysing and reporting the findings from such work. Instead, the lack of understanding of the extent and causes of shrinkage amongst practitioners and researchers is overlooked and various surveys are undertaken (for example Bamfield, 2004; Beck, 2004; Grasso, 2003; Hollinger and Langton, 2004) which use respondents' estimates to apportion shrinkage into causal categories. These findings are then widely reported with little attention given to their weaknesses.

One consequence of this situation is that policy makers in retail organisations use these findings to direct their shrinkage reduction strategies and budgets without realising their investment is based on received wisdom at best and collective falsehood at worst. The poor quality of the evidence underpinning decision making and action in the area of shrinkage serves only to highlight this area as a microcosm of poor practice in management research.

In light of this situation, this paper seeks to provide an informed base from which the issues relating to shrinkage can be better discussed. In particular the aim is to scope the subject area and identify the contextual issues that influence shrinkage measurement.

\section{Methodology}

The method to scope the contextual issues that influence shrinkage measurement draws on the work of Tranfield, Denyer and Smart (2003) on the development of evidenceinformed management knowledge. These researchers note that,

"Within management it will be necessary to conduct scoping studies to assess the relevance and size of the literature and to delimit the subject area or topic. Such studies need to consider cross-disciplinary perspectives and alternative ways in which a research topic has previously been tackled." - Tranfield et al (2003)

The methodological steps identified by Tranfield et al (2003) for conducting a scoping study capable of meeting the aim of this work are:

- Form a review panel to direct the process of investigation

- Iterate through a process of definition, clarification and refinement.

Aligning with the method proposed by Tranfield et al, a review panel was formed to direct the process of investigation. The academics on this panel had backgrounds in supply chain management, operations management, accountancy and criminology and so contained cross disciplinary perspectives on method and theory. The review panel also included practitioners working in the field, a characteristic recommended by Tranfield et al (2003). The fifteen practitioners on the panel came from a range of separate retail and manufacturing companies from across Europe. This panel meet on a bi-monthly basis and had done so for four years prior to this particular research being conducted.

The review of the literature base was a desk research exercise. This review was undertaken in three iterations of a procedure consisting of exploration of the theoretical base in the literature followed by a critique of this material by the review panel. This method approximates to deductive-inductive data analysis, i.e. the constant reflection of empirical against theoretical studies. 
Gaps in understanding highlighted by the review panel were addressed by the subsequent iteration of literature review. The output of this exercise was a consensus description of the contextual issues that influence shrinkage measurement.

These findings were presented at a seminar held as part of the 2004 ECR Europe Congress, which was attended by 210 people. The verbal and written feedback from this event was used as a gauge of the practical implications of the research.

\section{Delimiting Shrinkage}

Clarity and consistency are required when measuring in order to ensure that like is measured with like and that each measurement is compatible. Hence there is a need to delimit the term 'shrinkage' and to do so in a simple and clear manner.

In a simplistic view, the value of a product is a function of several factors including its being in the right place at the right time and possessing an appropriate level of quality. This value will be compromised if these factors fail to meet customer expectations. For example, if a product is damaged and its quality is compromised so its value will be reduced. Similarly, value can be reduced if goods are not available at the right time or if they are not in the right place. In the grocery retail environment the value of a good is represented by its intended sale price. Any loss of value in a product is assumed here to be represented through a mark down in its sales price.

The most extreme reduction in value is when it reduces to zero by writing off the product when it can no longer be sold. This can happen for the reasons described above and also when goods cannot be physically accounted for. Goods that cannot be accounted for will be identified when there is a discrepancy between book stock and physical stock. The book stock is the record of those goods held by the company and calculated as follows:

Book stock $=$ Results from last physical stock count + net movements

where,

net movements $=($ purchases + incoming transfers $)-($ sales + outgoing transfers $)$

Discrepancies between book stock and physical stock will come to light following a physical audit of a company's goods, such as a stock take. In a stock take the goods physically recorded in the audit are compared to the book stock and differences are recorded.

A retailer incurs a loss when a good is sold for less than its intended price, i.e. there is some intended sales income that was not realised and also when the intended sales income from products cannot be realised because of stock loss. It is proposed that these losses are what lie at the heart of the shrinkage issue. Therefore shrinkage will be delimited here as relating to:

\section{Intended sales income that was not and cannot be realised.}

This definition is intended to be clear and simple. This should allow the concept of shrinkage to be more easily communicated to the broad range of people that need to be engaged in addressing it. 


\section{Clarification and Refinement of Contextual Issues that Influence Shrinkage}

Several perspectives exist on the nature of shrinkage and any measurement system will be guided by the principles employed in its design. It is common for these guiding principles to be unspoken and for a measurement system to develop from them intuitively. In order to treat shrinkage measurement in a rational manner it is necessary to first consider the key perspectives that relate to retail shrinkage and explore lines of difference in how shrinkage can be viewed. Only once these perspectives have been addressed and decisions made on which guiding principles to adopt can measures be designed and deployed.

In order to clarify the debate on the contextual issues that influence shrinkage measurement, these issues were summarised into four categories, namely:

- Stewardship and performance improvement.

- Cost reduction and sales improvement.

- Local effects of systemic issues.

- The detailed nature of retailing.

Naturally there are limits to what can be achieved by reducing the debate to these four categories and these categories will no doubt benefit from refinement over time. However the merit in introducing this perspective on the subject is to introduce a series of lenses for viewing the richness of the subject. Each category is introduced and discussed below.

\section{Stewardship and Performance Improvement}

Shrinkage measurement can be viewed from the perspectives of 'stewardship' and 'performance improvement'. At their extremes, these two issues sit at opposite ends of a spectrum. The difference between them is that stewardship considers 'what is' while performance improvement considers 'what could have been.'

Stewardship implies the safe and conservative running of an operation along prescribed lines. Shareholders oblige the management team to be stewards of their invested capital and an accounting view of shrinkage is therefore typically geared towards stewardship. For example the stewardship perspective requires the value of goods to be conservatively represented as the lower of purchase cost or net realisable value.

Performance improvement implies delivering change to maximise return. Shareholders oblige management teams to maximise their return on investment, that is to protect and improve the value of their shareholding in a company and to ensure the company's long term profitability. In order to achieve this, the management team need to identify areas of sales and cost underperformance and direct effort to resolve them. Measurement from this perspective seeks to highlight forgone profits that result from shrinkage. 
The common ground between these two perspectives is that they both emphasise that decisions need to be based on reliable information. A common measurement system could satisfy both sets of requirements through collating and distributing performance data, which can then be manipulated to meet both sets of needs. In doing so, the managers would fulfil their dual roles as corporate stewards and as business leaders.

\section{Cost Reduction and Sales Improvement}

Shrinkage is a cost, and reducing this cost generally presents a profit opportunity in the grocery retail industry. Some observers and practitioners view shrinkage simply in terms of reducing this cost, however the profit opportunity available from effective shrinkage management extends further. Additional profit opportunities exist from increasing sales through improving the characteristics that shoppers seek. These characteristics include:

- Value for money shopping.

- On-Shelf Availability.

- One stop shopping.

- Good shopping experience.

- Safe visit.

Each retailer will have their own marketing mix that responds to and satisfies these characteristics in a variety of ways that are designed to best serve their market niche. Shrinkage reduction can affect these characteristics, resulting in an opportunity to increase sales. A description of the sales improvement opportunities associated with shrinkage reduction is presented in Table I below.

\section{Take in Table I}

In addition to the sales growth opportunities associated with reducing shrinkage, there are sales growth opportunities linked with operating a level of planned shrinkage. For example, optimal sales for some products result from having a quantity of unsold merchandise which are written off and disposed (Smith and Achabal, 1998). Recent examples of retail policies deployed despite increases in shrinkage include:

- Self scanning - a method where the shopper scans their own goods and pays for their shopping at an unstaffed checkout. This eliminates the need for a checkout operator and therefore reduces the retailer's staff costs. An example of the way self scan is used is for the shopper to take their basket of goods to an unstaffed checkout, scan and pack the goods themselves at the checkout and pay with cash or credit card at a payment point. Failure to scan some items seems to increase with this method, meaning that the retailer needs to offset the saving in staff costs against an increase in shrinkage.

- Fresh produce promotion - Some retailers differentiate themselves by having a full and well stocked range of fresh produce available at all times, which can lead to increased wastage.

Overall, the management of shrinkage needs to be recognised as having an effect on both retail costs and retail sales. It also raises the opportunity for profit enhancement through both reducing costs and providing the opportunity to enhance sales, which was an effect seen in project work by The Gillette Company and Tesco (Beck, Chapman and Peacock, 
2003). The implication is that effective shrinkage management needs to consider several factors that affect overall profitability, meaning that each factor needs to be measured.

\section{Local Effects of Systemic Issues}

Shrinkage may be considered as a series of unrelated local problems or as an issue that occurs as a result of a series of disparate factors coming together. That is, viewed in isolation, shrinkage incidents appear unconnected from one another and the response is to deal with them locally as and when they occur. However if incidents were viewed more broadly then common causes can be identified and then addressed through changes at a policy level. This systemic approach to shrinkage management points to viewing shrinkage as the symptom of a range of causes and to judge the influence of each cause using clear-cut criteria to inform decision-making and the selection of corrective actions.

Take for example the response when a case of bottles is dropped in the back of store. Taken in isolation, a localised view of shrinkage will result in the employee who dropped the case being reprimanded and the broken items cleared away. Viewed from a systemic perspective, this same incident is seen as being the consequence of several factors that combined in a critical way at the time of the incident. For example, the case of bottles was half full and unstable; The employee was in a hurry as they had been called away from shelf replenishment to serve on the busy checkouts; When the case of bottles was dropped, the employee was holding the case in one hand while using the other hand to make space on an already full warehouse shelf. None of these factors were individually critical but they conspired in a way that led to the incident. The ability to evaluate this incident and others like it provides the means to make decisions that can remove the underlying causes of shrinkage, preventing future loss from occurring.

In order to get a more rounded comprehension of shrinkage, the systemic perspective takes a broad view of events that considers issues relating to corporate policy that includes: product design; replenishment quantity and frequency; facility layout; recruitment, and; staff discipline.

The perspective of shrinkage as a systemic issue recognises that there can be significant distance and time-lag between where and when the causes of shrinkage were introduced, where the loss occurred and where and when the effect materialises. Therefore in order to understand and manage shrinkage it is necessary to look across a business and the life cycle of the elements to be found there. The life cycle of the various elements to a retail business can be broken into three horizons of long-term, medium-term and short-term. Long terms issues are those that are strategic in nature, typically designed in the infrastructure and are very difficult to change, such as the location and shape of a building. In the medium term there are some significant decisions that that are made within the constraints set down by design or strategy. Short term issues are tactical in nature and relate to the day-to-day running of operations. Table II below brings together the key elements of a retailing business that influence shrinkage and presents some of the key activities that occur within each of the three time horizons.

Take in Table II

Table II provides a framework for introducing a systemic perspective on shrinkage management. Instead of seeking to attribute the cause of an incident to one element of the 
table, the aim is to consider how the various aspects of the business affect shrinkage. This means that when it comes to addressing issues, the right parts of the business can be targeted at the right time.

Looking across the business there is a need to gather data on the performance of those activities that have an impact on shrinkage and this information needs to be brought together so it can be considered in its totality. Taking a store as an example, the measurement systems would assess long term issues linked to store design, medium term issues like the design of store procedures and short term issues like how these procedures are being followed. The role of this measurement system is to report results, such as the on the use of good practice, track trends over time and direct resources to where they will be most effective. The likelihood is that these resources will be managed at a local level, e.g. in-store, so the information needs to be specific and advice on what actions to take needs to be specific and relevant to that operation. In summary, the macro issues need to be deconstructed so they can guide timely intervention at the local level.

An example of where a systemic view of shrinkage is likely to benefit retail organisations is to use it to consider malicious losses, the loss due to internal and external theft and supplier fraud. At the localised level, success can be viewed as the detection of incidents, apprehension of perpetrators and ensuring the matter is dealt with in accordance to company policy. Good management would be seen as the ability to increase detection, apprehension and successful resolution. The systemic view on such incidents is not at odds with this approach, indeed effective and consistent execution of policy remains key. Where the systemic view on malicious loss differs is to engage a higher order of critical thinking and evaluate why malicious loss occurs. A difficulty with asking the 'why?' question is that it opens the door to a wealth of ideas that need to be carefully unpacked and considered. The multitude of divergent theories on malicious loss can be organised using Marcus's general taxonomic framework of general counterproductive behaviour (Marcus, 2001 reported in Marcus and Schuler, 2004). This framework is depicted in Figure 1 below.

Take in Figure 1.

The framework crosses two dichotomous distinctions: person verses situation; and control verses motivation which provides four quadrants, each of which are summarised under a heading.

Marcus and Schuler (2004) cite Hollinger and Clark's work on Theft by Employees (Hollinger and Clark, 1983) as being an example of research that sits within the theoretical area of situation - control that they term 'Opportunity'. This allows the systemic nature of shrinkage to be illustrated by considering internal theft from the opportunity perspective. To provide this illustration an opportunity is taken as being a situation that facilitates theft. The management challenge therefore lies in removing such situations. A systemic response to this challenge can be organised along the lines of the framework presented in Table II above. A list of actions needed to remove opportunity for internal theft and therefore reduce shrinkage is shown below in Table III.

Take in Table III 
The list of actions presented in Table III is not definitive and is intended to merely illustrate the point that actions are needed across the organisation and that these interventions occur at different times as well as places.

The relevance of this way of thinking on how shrinkage is measured is brought out by considering the response to catching a member of staff stealing. In the localised way of thinking the response is limited to having the person dismissed and an appropriate metric that would reflect this way of thinking would be measure the number of staff dismissals. In the systemic way of thinking, the incident would be evaluated in the particular store to judge the effectiveness of the local management team in implementing practices and procedures. At a wider level, details of the incident would be collected but the major difference lies in the way they are used. In this case the details of the incident are added to a pool of data, which is used to evaluate the validity of: the theoretical base that was drawn on; the frameworks used to operationalise the theories; the policies designed to remove the opportunity for theft by staff; and the effectiveness with which those policies were deployed.

\section{The Detailed Nature of Retailing}

The popular retailing adage that, 'retail is detail' resonates particularly well when it comes to shrinkage measurement. Shrinkage skews towards particular products (Clarke, 1999); locations (Bernstein, 1980); processes; people; and times (Beck and Chapman, 2003) so in order to identify where shrinkage is concentrated, data is required. This data comes at a price, i.e. the cost of gathering data, analysing it and disseminating information. Therefore a trade off exists between the benefit that data can bring and its associated costs.

An illustration of the problems that arise without data is found by returning to the issue raised earlier relating to industry surveys and the difficulties in attributing shrinkage to particular causes. A common practice when addressing shrinkage is to classify it using a set of four headings. Although the exact terms used differ between authors, the following headings used by Beck et al (2003) are representative:

- Process failures.

- Internal theft.

- External theft.

- Inter-company fraud.

Attributing known losses to these classifications is fairly straightforward. The problem arises with the inclination of business and academia to apportion a value for total shrinkage, i.e. known and unknown shrinkage, to these categories. Instead of an honest answer along the lines of, "Retailing is a complex business, there are many mechanisms through which shrinkage can occur and we don't know which ones apply in this instance," there is a tendency to use judgement / estimation / guess work to apportion unknown shrinkage to each category. Despite the fundamental weakness, this erratic approach is the default mechanism all too often used to inform management thinking and direct investments in loss prevention solutions when faced by a lack of hard data.

On balance, the benefits appear compelling for collecting data and converting unknown shrinkage into known shrinkage then deploying this data to direct corrective action. There 
is cost associated with implementing the systems required to gather and process the data however the insight this data provides into the nature and location of shrinkage provides the only sound basis for management action.

\section{Implications of Contextual Issues for Shrinkage Measurement}

Early drafts of this review of contextual issues surrounding shrinkage were presented to and critiqued by the review panel (as described above in the section on methodology). This panel examined the work to check factual accuracy, critique the way that the work was drawn together and to consider the implications of the review.

Broad support was given to the usefulness of framing the debate on shrinkage under the four headings presented above. This support was given as the headings allowed the debate on measurement to address fundamental and specific points whilst helping to retain the context needed when considering shrinkage.

Under stewardship and performance improvement, organisations report their shrinkage at either retail sales value or cost price but there is no consensus on whether one method is superior to the other. The common view is that each method has its merits but the key is to declare which approach has been used and to view the result accordingly. This view overlaps with the effect of shrinkage on both the costs and sales income of an organisation. The implication for measurement is that there is a need for reliable and timely information which can be interpreted to show how shrinkage impacts profitability through reducing sales income and to show how shrinkage affects profitability through increased costs.

Whilst each legal entity along a supply chain has responsibilities to its own stakeholders, the inter-firm nature of shrinkage means that companies need to work together. Shrinkage cuts across lines of managerial control and a strong case exists for viewing retail shrinkage as a systemic issue that spans the whole supply chain from raw material to checkout sale to product return. The implication is that visibility of performance across the supply chain is needed to view shrinkage from this broader context in order to identify where corrective action should be focussed. In order to guide management action, data needs to be available at the lowest level of granularity, that is by product; by location; and by time, and for this data to be shared with internal and external stakeholders. Whilst there is a cost associated with acquiring the capability to implement such a measurement system and to gather and share data, the implication is that this approach is necessary to convert unknown shrinkage into known shrinkage and to inform decision making.

These findings were presented to a seminar attended by 210 people held as part of the 2004 ECR Europe congress in Brussels, a mainly practitioner gathering. It is difficult to draw firm conclusions from the reaction given at such gatherings however a view of the practical implications of the research can be drawn from the feedback provided by attendees. An overall rating of the content of the seminar scored 4.4 out of 5. In context this gave the seminar the highest score out of the 12 seminars delivered on a variety of topics at the congress. Whilst this is a very rough instrument, this feedback suggests that this work has merit in the direction it takes the debate on shrinkage measurement, at least from a practitioner perspective. 


\section{Conclusions}

Shrinkage affects shoppers in a number of ways including reduced on-shelf availability, reduced assortment and defensive merchandising. None of these provide shopper satisfaction, hence sales are depressed and profits foregone. In addition to lost sales, shrinkage also affects the profits of grocery retailers and FMCG manufacturers through associated additional cost.

The scale of the impact on shoppers and on profit is sufficient to warrant senior management attention and investment in a performance measurement system to measure shrinkage. Such a system will fail to inform management decisions if it does not address the contextual issues that influence shrinkage measurement, namely:

- Stewardship and performance improvement.

- Cost reduction and sales improvement.

- Local effects of systemic issues.

- The detailed nature of retailing.

In particular, shrinkage measurement needs to be capable of capturing data in a way that allows it to be aggregated and disaggregated without losing its integrity, allowing alternative costing practices to be applied where necessary. Analysis of this data needs to factor in the systemic nature of shrinkage in order to attribute effect to cause and highlight areas of unsatisfactory performance and opportunities for improvement.

\section{References}

Bamfield, J. (2004) "Shrinkage, shoplifting and the cost of retail crime in Europe: a crosssectional analysis of major retailers in 16 European countries", International Journal of Retail \& Distribution Management, Vol 32 No 4/5, pp. 235

Beck, A. (2004) Shrinkage In Europe 2004: A Survey of Stock Loss in the Fast Moving Consumer Goods Sector, ECR Europe, Brussels.

Beck, A. and Chapman, P. (2003) Hot Spots in the Supply Chain, ECR Europe, Brussels.

Beck, A., Chapman, P. and Peacock, C. (2003) Shrinkage: A Collaborative Approach to Reducing Stock Loss in the Supply Chain, ECR Europe, Brussels

Bernstein, J.E. (1963) “Curbing Losses and Errors in Retail Store Operations”, New York Certified Public Accountant, October 1963, pp 706 - 714.

Bernstein, J.E. (1980) "Management Attitudes and Approaches Needed for the Control of Inventory Shortages”, Retail Control, Vol 48 No 6, pp 34.

Biemer, P.P. and Lyberg, L.E. (2003) Introduction to Survey Quality, Wiley-Interscience, Hoboken, NJ. 
Clarke, R.V. (1999) Hot Products: Understanding, Anticipating and Reducing Demand for Stolen Goods, Home Office Police Research Series paper 112, HMSO, London.

Donnell, J.D. (1975) "Merchant vs. Shoplifter in the Courts", Journal of Small Business Management, Vol 13, pp. 5-8.

Easterby-Smith, M., Thorpe, R. and Lowe, A. (1991) Management Research: An Introduction, Sage Publications Ltd. London.

Grasso, S. (ed.) (2003) $11^{\text {th }}$ Annual Retail Crime Survey 2003, British Retail Consortium, London

Hollinger, R.C., and Clark, J.P. (1983) Theft by employees, Lexington Books, Lexington, MA.

Hollinger, R.C. and Langton, L. (2004) 2003 National Retail Security Survey, University of Florida, Gainesville, FL.

Marcus, B and Schuler, H. (2004) “Antecedents of Counterproductive Behavior at Work: A General Perspective”, Journal of Applied Psychology, Vol 89 No 4, pp. 647-660

Neely, A.D. (1999) "The performance measurement revolution: why now and where next”, International Journal of Operations and Production Management, Vol 19 No 2, pp. 205-28.

Oliphant, B.J. and Oliphant, G.C. (2001) "Using a Behaviour-Based Method to Identify and Reduce Employee Theft”, International Journal of Retail \& Distribution Management, Vol 29 No 10, pp $442-451$.

Ross, L. and Anderson, C.A. (1982) "Shortcomings in the Attribution Process: On the Origins and Maintenance of Erroneous Social Assessments", in Kahneman, D., Slovic, P. and Tversky, A. (Ed.), Judgement Under Uncertainty: Heuristics and Biases, Cambridge University Press, Cambridge, pp.129-152.

Smith S.A. and Achabal, D.D. (1998) "Clearance Pricing and Inventory Policies for Retail Chains”, Management Science, Vol 44 No 3, pp 285-300.

Tranfield, D., Denyer, D. and Smart, P. (2003) “Towards a Methodology for Developing Evidence-Informed Management Knowledge by Means of Systematic Review”, British Journal of Management, Vol 14, pp. 207-222 


\begin{tabular}{|l|l|}
\hline \multicolumn{1}{|c|}{ Characteristic } & \multicolumn{1}{c|}{ Shrinkage Reduction Sales Improvement Opportunities } \\
\hline $\begin{array}{l}\text { Value for money } \\
\text { shopping }\end{array}$ & $\begin{array}{l}\text { Reduction in shrinkage costs and cost effective shrinkage } \\
\text { management leveraged to reduce price of goods and drive sales. }\end{array}$ \\
\hline $\begin{array}{l}\text { On-Shelf } \\
\text { Availability }\end{array}$ & $\begin{array}{l}\text { Automated store replenishment triggers reordering when sales } \\
\text { reduce recorded inventory below a threshold. Shrinkage can cause } \\
\text { stock outs to occur before the inventory reordering threshold is } \\
\text { reached. Once this situation is reached further sales cannot occur. } \\
\text { Replenishment will not be triggered until the inventory record is } \\
\text { manually reset. Reduction in shrinkage will improve OSA, which } \\
\text { will improve sales. }\end{array}$ \\
\hline One stop shopping & $\begin{array}{l}\text { Fear of shrinkage can prevent retailers stocking items perceived as } \\
\text { being at risk. Overcoming the threat of shrinkage encourages the } \\
\text { retailer to stock a wide assortment. }\end{array}$ \\
\hline $\begin{array}{l}\text { Good shopping } \\
\text { experience }\end{array}$ & $\begin{array}{l}\text { Fear of shrinkage can lead retailers to defensively merchandise } \\
\text { products. Removing the causes of shrinkage and implementing } \\
\text { alternative solutions that counter the threat of shrinkage can allow } \\
\text { goods to be openly merchandised. Open merchandising improves } \\
\text { the shopping experience and tends to increase sales. }\end{array}$ \\
\hline Safe visit & $\begin{array}{l}\text { Overt security measures and a hard-line attitude by employees can } \\
\text { promote a perception amongst shoppers that there is a threat to } \\
\text { safety. Sensitive yet robust operations management can provide a } \\
\text { safe environment in which to work and shop that is compatible with } \\
\text { a good shopping experience. }\end{array}$ \\
\hline
\end{tabular}

Table I. Shrinkage Reduction Sales Improvement Opportunities 


\begin{tabular}{|c|c|c|c|c|}
\hline & \multicolumn{3}{|c|}{ Temporal Stages } \\
\hline & & Long-term & Medium-term & $\begin{array}{l}\text { Short-term } \\
\end{array}$ \\
\hline \multirow{2}{*}{$\frac{\mathscr{d}}{\pi}$} & Store & $\begin{array}{l}\text { - Plan location. } \\
\text { - Develop layout. }\end{array}$ & $\begin{array}{l}\text { Introduce new } \\
\text { processes and } \\
\text { practices. }\end{array}$ & $\begin{array}{l}\text { - Process and practice } \\
\text { adherence. } \\
\text { - Incident management. }\end{array}$ \\
\hline & $\begin{array}{l}\text { Supply } \\
\text { chain }\end{array}$ & $\begin{array}{l}\text { - Supply chain network } \\
\text { design. } \\
\text { - Distribution centre } \\
\text { design. } \\
\end{array}$ & $\begin{array}{l}\text { - Supplier selection. } \\
\text { - Introduce new } \\
\text { processes and } \\
\text { practices. } \\
\end{array}$ & $\begin{array}{l}\text { - Process and practice } \\
\text { adherence. } \\
\text { - Incident management. }\end{array}$ \\
\hline \multicolumn{2}{|c|}{ Product } & $\begin{array}{l}\text { - Product design. } \\
\text { - Packaging design. }\end{array}$ & • Purchasing. & $\begin{array}{l}\text { - Integrity of product } \\
\text { from raw material to } \\
\text { sale at checkout. } \\
\text { - Returns. } \\
\text { - Incident management. }\end{array}$ \\
\hline \multicolumn{2}{|c|}{ People } & $\begin{array}{l}\text { - Create human resource } \\
\text { policies. }\end{array}$ & $\begin{array}{l}\text { - Recruitment. } \\
\text { - Training. }\end{array}$ & $\begin{array}{l}\text { - Audit. } \\
\text { - Accountability. } \\
\text { - Action. } \\
\text { - Attitude. } \\
\end{array}$ \\
\hline \multicolumn{2}{|c|}{ ICT systems } & - System design. & $\begin{array}{l}\text { - Supplier selection. } \\
\text { - New system } \\
\text { implementation. } \\
\text { - System upgrade. }\end{array}$ & $\begin{array}{l}\text { - Process and practice } \\
\text { adherence. } \\
\text { - Incident management. }\end{array}$ \\
\hline
\end{tabular}

Table II. A List of Key Issues that Influence Shrinkage 


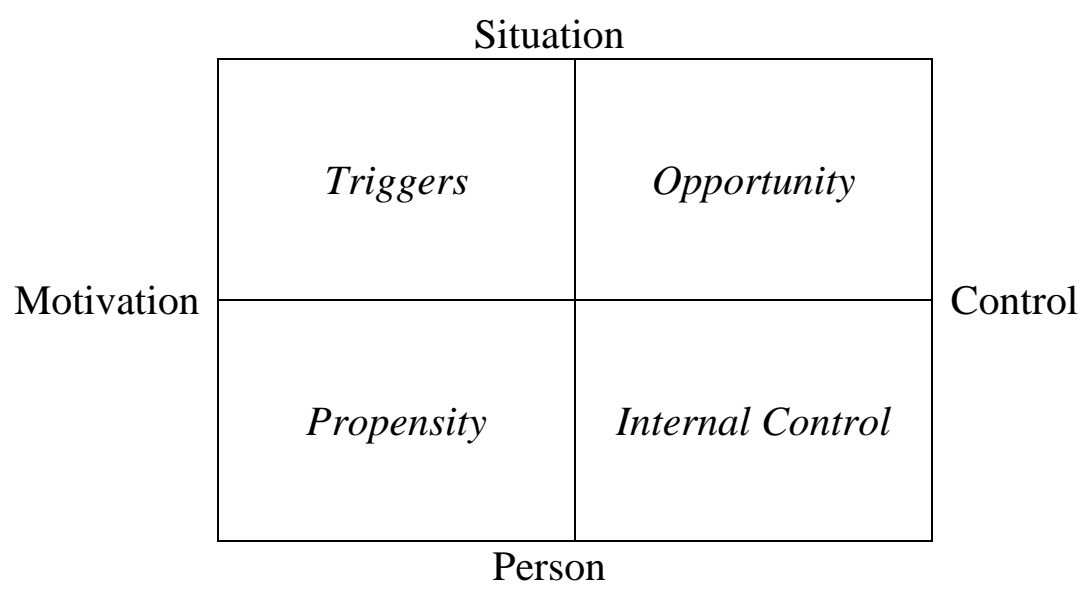

Figure 1. A Taxonomic Framework for General Counterproductive Behaviour (from Marcus and Schuler, 2004). 


\begin{tabular}{|c|c|c|c|c|}
\hline & \multicolumn{3}{|c|}{ Temporal Stages } \\
\hline & & Long-term & Medium-term & Short-term \\
\hline \multirow{2}{*}{$\frac{\mathscr{U}}{\tilde{a}}$} & Store & $\begin{array}{l}\text { Remove opportunity for } \\
\text { shrinkage through design } \\
\text { of front and back of store } \\
\text { and staff areas to increase } \\
\text { visibility and delineate } \\
\text { areas of stock } \\
\text { accountability. }\end{array}$ & $\begin{array}{l}\text { Design and implement } \\
\text { processes and practices } \\
\text { to: } \\
\text { - Segregate and manage } \\
\text { Hot Products. } \\
\text { - Operationalise the '4 } \\
\text { As' (see People). } \\
\text { - Ensure compliance. }\end{array}$ & $\begin{array}{l}\text { - No discretion on } \\
\text { adherence to process } \\
\text { and good practice. } \\
\text { - Daily audit and } \\
\text { maintenance of store } \\
\text { standards. } \\
\text { - Incident management. }\end{array}$ \\
\hline & $\begin{array}{l}\text { Supply } \\
\text { chain }\end{array}$ & $\begin{array}{l}\text { Remove opportunity for } \\
\text { shrinkage through: } \\
\text { - Designing capable } \\
\text { processes. } \\
\text { - Collaborating with } \\
\text { supply chain partners. }\end{array}$ & $\begin{array}{l}\text { Design and implement } \\
\text { processes and practices } \\
\text { to: } \\
\text { - Segregate and manage } \\
\text { Hot Products. } \\
\text { - Operationalise the ‘4 } \\
\text { As' (see People). } \\
\text { - Ensure compliance. }\end{array}$ & $\begin{array}{l}\text { - No discretion on } \\
\text { adherence to process } \\
\text { and good practice. } \\
\text { - Daily audit and } \\
\text { maintenance of DC and } \\
\text { transport standards. } \\
\text { - Incident management. }\end{array}$ \\
\hline \multicolumn{2}{|c|}{ Product } & $\begin{array}{l}\text { Remove opportunity for, } \\
\text { \&/or increase visibility } \\
\text { of, shrinkage through } \\
\text { product and packaging } \\
\text { design, e.g. tamper proof / } \\
\text { evident packaging. }\end{array}$ & $\begin{array}{l}\text { - Purchasing: align } \\
\text { supply with demand to } \\
\text { prevent overstocking. }\end{array}$ & $\begin{array}{l}\text { Regular counting of } \\
\text { product for real-time } \\
\text { detection of loss. }\end{array}$ \\
\hline \multicolumn{2}{|c|}{ People } & $\begin{array}{l}\text { Ensure senior } \\
\text { management engagement. } \\
\text { Remove opportunity for } \\
\text { shrinkage through design } \\
\text { of: } \\
\text { - Incentives. } \\
\text { - Policy on staff } \\
\text { searches. } \\
\text { - Policy on theft. }\end{array}$ & $\begin{array}{l}\text { - Recruitment, e.g. take } \\
\text { up references. } \\
\text { - Training and awareness } \\
\text { of policies and } \\
\text { practices. } \\
\text { - Ensure compliance. }\end{array}$ & $\begin{array}{l}\text { Maintain daily focus on } \\
\text { shrinkage through the ‘ } 4 \\
\text { As' of: } \\
\text { - Audit. } \\
\text { - Accountability. } \\
\text { - Action. } \\
\text { - Attitude. }\end{array}$ \\
\hline \multicolumn{2}{|c|}{ ICT systems } & $\begin{array}{l}\text { Remove opportunity for } \\
\text { shrinkage through } \\
\text { designing capable } \\
\text { processes. }\end{array}$ & • Ensure compliance. & $\begin{array}{l}\text { - No discretion on } \\
\text { adherence to process } \\
\text { and good practice. } \\
\text { - Incident management. }\end{array}$ \\
\hline
\end{tabular}

Table III. A List of Actions to Remove the Opportunity for Internal Theft 